\title{
LA FRONTERA PORTÁTIL: NACIÓN Y TEMPORALIDAD EN LASTARRIA Y SARMIENTO ${ }^{1}$
}

POR

Álvaro Fernández Bravo

Temple University

Cayó el despotismo de los reyes y quedó en pie con todo su vigor el despotismo del pasado

Lastarria

El nacionalismo cultural adoptó en el Cono Sur de América Latina una persistente voluntad por delimitar el perímetro de inclusión de las emergentes estructuras políticas. Los relatos que intentaban dotar de sentido la transición de la colonia al momento poscolonial buscaron producir narraciones útiles para definir sus naciones en el espacio y en el tiempo. La dimensión temporal de la Nación fue uno de los problemas más atractivos para los letrados, interesados por fijar conceptualmente ese objeto intangible. Las fronteras territoriales del Estado no significaron en esta temprana etapa una zona de atención; se trataba de desentrañar en el pasado las raíces de la nacionalidad y más aún: emplear el tiempo como una herramienta para modelar una identidad de contornos imprecisos. ${ }^{2}$

Estudiar la posición de las fronteras cronológicas de la nación permite hacer visible la forma que adquirió ese objeto maleable, estratégicamente manipulado por la imaginación literaria. La constitución de nuevas unidades políticas llevó a las elites latinoamericanas a preguntarse por la historia de sus comunidades y a buscar relatos que articularan el período que llegaba a su fin con la nueva etapa. La duración de la nación se convirtió en objeto de narraciones que al reescribir su trayectoria proponían un vínculo diferente entre el pasado y el presente.

\footnotetext{
' Este artículo fue posible en parte gracias a un Grant in Aid for Publication de la Universidad de Temple.

${ }^{2}$ Para la relación entre nación y temporalidad véanse Johannes Fabian, Time and the Other: How Anthropology Makes its Object (New York: Columbia University Press, 1983) y Walker Connor, "When is a Nation?" publicado en Ethnic and Racial Studies, 13/1 (1990) 92-100; para la relación entre historia y nacionalidad Michel De Certeau, The Writing of History (New York: Columbia University Press, 1988) y Andrew Woll, A Functional Past: The Uses of History in Nineteenth Century Chile (Baton Rouge: Louisiana State University Press, 1982).
} 
Los años 40 del siglo XIX reúnen en Santiago de Chile algunas de las figuras más activas de la cultura latinoamericana. ${ }^{3}$ La presencia de Andrés Bello y la llegada de los exiliados argentinos agita la atmósfera cultural y desata la polémica. El problema de la producción de un capital cultural ingresa rápidamente en discusión y de inmediato surge la pregunta por los materiales que deberán nutrir a esa literatura que aparecía como un componente imprescindible de toda nación moderna. ¿Hacia dónde debían dirigir su mirada los letrados encargados de producir la representación de la Nación? O para decirlo con las palabras de José Victorino Lastarria en 1842: “¿Qué modelos literarios serán, pues, los más adecuados a nuestras circunstancias presentes?"4

Esta pregunta ya había sido planteada y respondida por Andrés Bello un año antes cuando recomendaba entusiasmado encontrar ese modelo literario en La Araucana, "la Eneida de Chile (1/4), único hasta ahora de los pueblos modernos cuya fundación ha sido inmortalizada por un poema épico" (1841:106). ${ }^{5}$ Según Bello, Chile poseía en el relato de Ercilla una ventaja sobre otros "pueblos modernos". Con el propósito de establecer la genealogía de una tradición propia, los letrados debían necesariamente buscar en el pasado - y en la celebración épica de la conquista- los materiales para la construcción de una literatura propia.

Sin embargo las palabras de Bello reflejan una posición difícilmente aceptable por sus interlocutores. La percepción de la temporalidad de la nación como una continuación rectilínea de la etapa colonial española resulta en este momento una idea por completo ajena a los jóvenes letrados, ansiosos de promover una separación entre el presente nacional y el pasado colonial. Leer la fundación de la identidad chilena en La Araucana, como hace Bello, significa aproximarse demasiado a la tradición española de la que los letrados consideraban preciso distanciarse.

Lastarria afirma en ese mismo discurso de 1842:

[M]uy poco tenemos que imitar: nuestra literatura debe sernos exclusivamente propia, debe ser enteramente nacional. Hay una literatura que nos legó España con su religión divina, desfigurada por el fanatismo, con sus pesadas e indigestas leyes, con sus funestas $\mathrm{y}$ antisociales preocupaciones. Pero esa literatura no debe ser la nuestra, porque al cortar las cadenas enmohecidas que nos ligaron a la Península, comenzó a tomar otro tinte muy diverso nuestra nacionalidad (ibid).

Hay en estas palabras un rechazo del legado cultural español y también un problema de orden: la emancipación marca una transformación política que debe verse reflejada en la vida social. Lastarria - y según veremos también Sarmiento- entiende que el orden

\footnotetext{
${ }^{3}$ Véase Luis A. Romero, "Sarmiento, testigo y testimonio de la sociedad de Santiago" y Norman P. Sacks, "Lastarria y Sarmiento: el chileno y el argentino achilenado", ambos publicados en Revista Iberoamericana, $\mathrm{N}^{\circ} 143$ (1988) 461-475 y 491-512.

${ }^{4}$ José Victorino Lastarria, "Discurso de incorporación a una sociedad literaria de Santiago, pronunciado en la sesión del 3 de mayo de 1842" en Miscelánea historica y literaria, tomo II (Valparaíso: Imprenta La Patria, 1868 [1842]: 5-26) 15.

${ }^{5}$ Andrés Bello, Obras Completas, tomo VII, Opúsculos literarios y Críticos (Santiago: Imprenta Pedro G. Ramírez, 1884) 141.
} 
vigente no cumple acabadamente los objetivos de la independencia. En el orden actual conviven leyes y costumbres que deberían separarse: colonia y nación, Europa y América representan conceptos antagónicos que conspiran contra la necesaria homogeneidad de la Nación. Estos dos conjuntos semánticos deben diferenciarse porque sólo así será posible establecer una identidad poscolonial específica, distinta de la metrópoli.

En su polémica sobre la lengua con Andrés Bello y sus discípulos, Sarmiento defendió desde una posición comparable a la de Lastarria el derecho soberano de los pueblos a crear su propia lengua, ya que "el idioma de un pueblo es el más completo monumento histórico de sus diversas épocas y de las ideas que lo han alimentado". ${ }^{6}$ Frente a la preocupación de Bello sobre el peligro de convertir al español en un idioma "jenízaro y mestizo," Sarmiento alega en favor de la impureza lingüística como un modo de afirmar una especificidad respecto de la ex metrópoli. ${ }^{7}$

Al abogar en favor de una lengua escrita que reflejara con mayor fidelidad el habla popular de los chilenos, Sarmiento no sólo desafiaba el apego a la norma peninsular recomendada por el intelectual caraqueño sino que consideraba éste un gesto necesario para la independencia cultural. Para Sarmiento era preciso aproximar la identidad lingüística a los usos característicos de la nación —en particular el habla de las ciudades, usinas de civilización permeables a las costumbres europeas. Deshispanizar las costumbres mediante la incorporación de habitus locales - preferentemente urbanos- europeos a la lengua nacional no podía tener sino un efecto saludable y modernizador para las nuevas naciones del continente. ${ }^{8}$

Tanto en Sarmiento como en Lastarria funciona una voluntad por establecer fronteras que contribuyan a recortar una identidad nacional necesariamente alejada del pasado español. Pero esta empresa rápidamente se estrella con la presencia perdurable del mundo colonial en la legislación, costumbres e instituciones de las nuevas naciones. Ese tiempo demasiado breve transcurrido desde la independencia no había bastado para borrar las huellas que señalan continuamente el pasado del que los letrados consideraban urgente despojarse. Ante este hecho consumado los escritores ensayan distintas soluciones que, según veremos, apelan a fronteras más o menos restrictivas, destinadas a modelar la forma de la nación que mejor se ajuste a sus respectivos proyectos.

La estrategia de Lastarria puede observarse con mayor nitidez en el ensayo que escribiera en 1844, titulado Investigaciones sobre la influencia social de la conquista y el sistema colonial de los españoles en Chile. ${ }^{9}$ astarria escribe sus Investigaciones como respuesta a una convocatoria de la Universidad y con el propósito de rastrear la genealogía de la Nación en el pasado colonial. Pero en contraste con la sugerencia de su maestro Andrés

\footnotetext{
${ }^{6}$ Norberto Pinilla, La controversia filológica de 1842 (Santiago de Chile: Prensas de la Universidad de Chile, 1945) 42.

${ }^{7}$ Véase Carlos Altamirano y Beatriz Sarlo, Ensayos argentinos: De Sarmiento a la vanguardia (Buenos Aires: CEAL, 1983) 43 y ss.

${ }^{8}$ Tulio Halperín Donghi lo puso en estos términos: Si España es el problema, Europa es la solución. El espejo de la historia (Buenos Aires: Sudamericana, 1987) 198.

${ }^{9}$ Incluido en su Miscelánea Histórica y literaria, tomo I (Valparaíso: Imprenta de La Patria, 1868) 1-136.
} 
Bello, no establece una línea de continuidad entre la épica colonial hispánica y el presente, sino que se interesa más bien por la confrontación entre europeos e indígenas como una zona de formación de la subjetividad chilena. El ensayo localiza en el "pasado étnico" una zona donde explorar los orígenes de la nacionalidad. ${ }^{10}$ Lastarria navega confiado por la aguas de la paradoja cuando se propone simultáneamente estimular un corte con el pasado y localizar en él un origen de la nacionalidad chilena.

Este proyecto ambivalente, que procura liberarse del pasado pero no logra cesar de buscar en él claves para entender el presente y edificar el futuro, puede ser interpretado en el marco del horror vacui que sobrevino a las clases letradas con la desintegración del orden colonial. Sin duda la repentina apertura generada por la independencia no significó un don fácilmente manejable para aquellos que querían reemplazar el antiguo régimen y ahora enfrentaban la tarea de proveer un argumento para la trancisión. Necesariamente la mirada se vuelve hacia el pasado ( $\mathrm{y}$ también hacia la naturaleza, la otra cantera a la que acuden los letrados en búsqueda de materiales para escribir la literatura nacional). Sin embargo ese pasado no será un tiempo exánime sino un espacio estratégico donde atrincherarse para atacar el orden vigente y denunciar la pervivencia de estructuras arcaicas.

Lastarria presta especial atención a la etnicidad como un modo de iluminar una cara de la conquista antagónica con la historia colonial. Pero las Investigaciones acuden allí no con el propósito de exhumar el pasado e hilvanarlo mansamente con el presente, como quería Bello, sino para reinterpretarlo: reemplazar el tiempo colonial por otro tiempo más útil a una nación moderna, menos condescendiente con los ejecutores de la conquista y poblado de indígenas en guerra permanente con el invasor europeo. La resistencia araucana será territorializada y ubicada de este lado de las fronteras cronológicas: la nación precisa héroes y su panteón no puede ser el mismo de la metrópolis colonial. A pesar de las indignadas protestas que esta operación despertó, una prolífica tradición historiográfica se hizo eco del gesto de Lastarria. La vocación pedagógica de esta estrategia discursiva fue eficaz y la resistencia araucana ha persistido en la cultura chilena como una representación de la nacionalidad. ${ }^{11}$

No obstante, sería ingenuo suponer que esta maniobra respondía simplemente a una precoz voluntad multiculturalista interesada en contestar el rampante etnocentrismo de los letrados decimonónicos. Lastarriay Sarmiento actuaban movidos por el deseo de modernizar sus naciones, aunque sin conseguir escapar a la contradicción de buscar las marcas de la identidad en costumbres o acontecimientos ligados a un tiempo que consideraban necesario dejar atrás.

El interés por las culturas indígenas en las Investigaciones tiene una función pragmática y contingente; esa "inclusión" del componente étnico en la narración de la nación no

\footnotetext{
${ }^{10}$ Véase Anthony D. Smith, "Gastronomy or geology? The role of nationalism inthe reconstruction of nations" en Nations and Nationalism, vol 1, part 1 (march 1995) 3-23.

"Lastarria dice en sus Recuerdos Literarios: "Había tenido que hacerme literato para ausiliarme con este propósito con todas las formas del arte y combatir el pasado colonial, hiriéndolo, chocándolo, sublevando contra él las antipatías de la nueva generación". Recuerdos Literarios (Santiago: Librería de M. Servat, 1885[1878]) 46. La lucha por el control del sentido supone que quien triunfe podrá imponer su relato en un nivel pedagógico sobre las jóvenes generaciones.
} 
significa que su perspectiva sea radicalmente distinta de la de sus contemporáneos. Si como dice Efraín Kristal "Lastarria does not seems to differentiate Chileans of European descent like himself from the indigenous populations", ${ }^{12}$ en realidad el ensayo sí impone una distancia. Se trata precisamente del proceso de temporalización cuyos efectos suponen una mitologización nacionalista de la resistencia araucana y la consecuente ubicación de ese ícono de la nacionalidad en un punto remoto (e inofensivo) del tiempo. Las Investigaciones, al reclamar una frontera entre el tiempo de la Nación y el tiempo de la Colonia, reifican esas piezas que buscan ser ordenadas en una nueva secuencia. Hay un uso arqueológico de los indígenas que, despojados de toda connotación bárbara, no interesan como un sujeto histórico, sino más bien por una posición ideológica que permite oponer una línea diferente de conexión con el pasado, útil para la narración de la nación.

Sarmiento se encontraba entonces en Chile y en parte gracias a la ayuda de Lastarria ${ }^{13}$ se había convertido en un dinámico partícipe de la vida cultural de la ciudad. Su reseña de las Investigaciones, publicada en El Progreso el 27 de septiembre de 1844, es una pieza de sumo interés ya que el calor de la polémica descubre el modelo de nación imaginado y la localización de sus fronteras. Por otra parte, la proximidad temporal del artículo con la publicación del Facundo permite reconocer algunas de las ideas que serían desplegadas en la obra máxima del escritor argentino. ${ }^{14}$

El problema de las fronteras cronológicas articula el eje de la crítica de Sarmiento. Incorporar el componente indígena al imaginario nacional entraña un riesgo que la reseña se apresura a denunciar. Dice al respecto:

Según se deja traslucir aun por el título mismo de la obra, el autor considera la conquista española como un hecho que ha venido a influir sobre la sociedad chilena; así, le vemos llenarse de santo y patriótico entusiasmo, al recordar la heroica resistencia araucana, y llenarse de indignación al detallar los medios que los españoles tocaban para escarmentar a sus enemigos (1/4). El autor no ha podido en estos conceptos emanciparse de las ideas que puso en boga la revolución de la independencia para azuzar los ánimos contra la dominación española, mintiendo una pretendida fraternidad con los indios, a fin de ponernos en hostilidad con nuestros padres, a quienes queríamos arrojar de América; así, pues, nos envanecíamos de "la cordura de Colocolo, de la prudencia y fortaleza de Caupolicán, de la pericia y el denuedo de Lautaro, de la ligereza y osadía de Painenancu", como si estos hombres salvajes perteneciesen a nuestra historia americana, y como si Arauco, después de la revolución, como durante el coloniaje, no fuese un país fronterizo y una nación extraña a Chile y su capital e implacable enemigo, a quien Chile ha de absorber, destruir, esclavizar, ni más ni menos que lo habrían hecho los españoles (217).

\footnotetext{
${ }^{12}$ Efraín Kristal, "Dialogues and polemics: Sarmiento, Lastarria and Bello" en Joseph T. Criscenti, Sarmiento and his Argentina (Boulder: Lynne Rienner Publishers, 1993) 61-70, 66.

${ }^{13}$ Ver Sacks 1988: 492-93.

${ }^{14} \mathrm{El} \mathrm{Facundo} \mathrm{se} \mathrm{comienza} \mathrm{a} \mathrm{publicar} \mathrm{en} \mathrm{agosto} \mathrm{de} 1845$ y la reseña de las Investigaciones el 27 de septiembre de 1844, en el mismo periódico donde se publica el artículo que me interesa ahora. Véase Sarmiento, Obras Completas, Tomo II, Artículos críticos y literarios (Buenos Aires: Editorial Luz del día, 1848) 215-222.
} 
Su lectura acepta la utilidad coyuntural de la retórica indigenista tal como fue empleada durante la independencia pero se resiste a reconocerle una función idéntica en el presente. Para Sarmiento no sólo es preciso abandonar la estrategia empleada entonces sino que la nación debe asumir como propia la política expansionista de la colonia. Si durante la independencia se trataba de acumular fuerzas para "arrojar a nuestros padres de América", apelar a un pacto - y nótese que se trata sobre todo de un "pacto discursivo"; Sarmiento no habla de "hechos" sino de representaciones - con la barbarie en nombre de la emancipación acaso pudo estar justificado. Pero rechaza terminantemente prolongar esa alianza contingente en la actualidad: los indígenas deben ser expulsados incluso de "nuestra historia americana". Durante las guerras de la independencia pudo haberse acudido a medios infames en nombre de un objetivo legítimo pero ese tiempo ha terminado; la temporalidad de la nación debe distanciarse de esa ficción e inventar una nueva donde no hay espacio para la canonización de la barbarie indígena, ni siquiera en el relato de la historia. La irritación de Sarmiento debe leerse sin embargo como índice de su propia fascinación por el Otro como un campo semántico donde la identidad se define negativamente. Lastarria proclama que no somos españoles; Sarmiento le responde que tampoco somos indígenas. ${ }^{15}$

El eje del cuestionamiento del argentino radica en que la discusión sobre el pasado encierra un debate sobre el presente. La estrategia de temporalización de las Investigaciones suponía prolongar la alianza simbólica con la barbarie que fue precisamente una de las estrategias del gobierno de Rosas, que organizó sus milicias apoyándose en ese pacto y que había negociado la paz con las tribus indígenas, posponiendo la definición de los conflictos fronterizos que estallarían en las décadas siguientes. Sarmiento veía en su país un efecto inaceptable de la propuesta cultural de Lastarria. Dice al respecto:

Cuando uno lee a Ercilla y oye repetir hoy día aquellas imaginadas virtudes de Colocolos y Lautaros, está a punto de creer que los antiguos araucanos eran otro pueblo distinto de los araucanos que conocemos nosotros; de esos salvajes del sur, borrachos, estúpidos, crasos e ignorantes, y sin sentimiento alguno de dignidad, salvo el gusto por ser independientes, que es distintivo de las tribus salvajes. ¿Cuántos Colocolos, Lautaros y Caupolicanes lancean todos los días a nuestros soldados de la frontera? Y estos héroes de nuestra historia ¿qué algazara feroz no armarían, si Concepción cayese una hora en sus manos? ¿Y eso por odio a la dominación española? No; es preciso no ser candorosos; por amor a la rapiña, por sus instintos salvajes de matanza y destrucción (220).

El fragmento rechaza la distribución temporal desarrollada en el ensayo porque aunque comparte el propósito de responder la pregunta por las fronteras de la identidad, se niega a reconocer en las culturas indígenas un antecedente del presente. Sarmiento lee lo que el texto calla: que los indígenas que resistieron la conquista española son los mismos que ahora resisten la expansión de los estados chileno y argentino. Y alude a un conflicto que ya se perfilaba en el horizonte: la guerra de fronteras que explotaría en los años siguientes ${ }^{16}$ y la

\footnotetext{
${ }^{15}$ Edward Said ha estudiado este mecanismo en Orientalism (New York: Vintage Books, 1979) 53 y ss.

${ }^{16}$ Las guerras de expansión colonial instrumentadas desde las naciones encontraron una justificación ideológica en las narraciones de la identidad que habían territorializado el pasado. Este gesto proveyó
} 
amenaza que él veía en plena operación en su patria: las hordas salvajes ocupando las ciudades y haciendo retroceder en el tiempo las costumbres de los centros que debían irradiar la luz de la civilización sobre el cuerpo nacional.

La invención de la Nación impulsó a los letrados latinoamericanos a investigar las fronteras de la identidad aunque el resultado de ese viaje parece promover más preguntas que las que aspiraba responder. Sarmiento y Lastarria comprendieron que descolonizar la cultura nacional era un paso ineludible para diseñar una nación moderna y preferentemente homogénea. Sin embargo para promover ese distanciamiento debieron zambullirse en el tiempo y armar desde allí relatos que despertaron la polémica. Las estrategias para alcanzar esa meta fueron diferentes y permiten reconstruir un itinerario ideológico. Mientras Sarmiento encontró en la lengua bastarda y urbana (Pinilla 46) la representación de una identidad en conflicto, Lastarria propone una nueva organización del pasado étnico como el antídoto para distinguir los tiempos yuxtapuestos de la nación y la colonia. En ambos casos las fronteras cronológicas delimitadas en los relatos permiten reconocer quienes merecían pertenecer y quienes no a ese territorio conceptual en proceso de definición.

argumentos a la consideración de los indígenas como ciudadanos "rebeldes" y a las regiones ocupadas por las tribus como fragmentos circunstancialmente separados del cuerpo nacional. Said califica estos discursos como productores de "obligaciones metafisicas" que dotan a las naciones de un argumentación ideológica para la expansión imperialista que tuvo lugar durante el siglo XIX. Culture and Imperialism (New York: A. Knopf, 1993) 10. 
